\title{
Estuarine soundscapes: distinct acoustic characteristics of oyster reefs compared to soft-bottom habitats
}

\author{
Ashlee Lillis*, David B. Eggleston, DelWayne R. Bohnenstiehl \\ Department of Marine, Earth \& Atmospheric Sciences, North Carolina State University, Raleigh, North Carolina 27695-8208, USA
}

ABSTRACT: Different types of benthic habitats likely produce distinct soundscapes due to differences in the physical and biological contributors to ambient sound. Despite their potential importance to ecological processes such as larval settlement, the soundscapes of most coastal and estuarine habitats have not been characterized. We investigated whether an estuarine soundscape is a reliable indicator of habitat type by measuring the sounds of oyster reefs and nearby off-reef soft-bottom areas in Pamlico Sound, North Carolina, USA. Acoustic sampling in 3 areas across the estuary revealed distinct acoustic patterns in oyster reef habitats compared to surrounding offreef areas, with reef soundscapes dominated by snapping shrimp sounds and the vocalizations of reefdwelling fish species. Compared to soft-bottom habitat, oyster reefs had significantly higher sound pressure levels in the $2-23 \mathrm{kHz}$ frequency band and higher acoustic diversity index values at each concurrent sampling event. Spectral differences between adjacent reef/off-reef habitats were present throughout the summer and fall sampling season and across 2 sampling years, but the acoustic signal strength differed between reef sites. Passive sound propagation surveys found that the distinct acoustic characteristics of oyster reefs within the $2-23 \mathrm{kHz}$ frequency band were highly localized, with effective source levels of 108.8 to $120.0 \mathrm{~dB}$ re $1 \mu \mathrm{Pa} @ 1 \mathrm{~m}$ and transmission loss approximating a cylindrical geometric spreading model. This soundscape characterization study suggests that spatial heterogeneity in ambient sound could serve as a reliable indicator of habitat type and potentially convey habitat quality information to dispersing organisms.

KEY WORDS: Passive acoustics - Soundscape ecology · Habitat-associated sound · Acoustic diversity $\cdot$ Pamlico Sound $\cdot$ Subtidal oyster reef

Resale or republication not permitted without written consent of the publisher

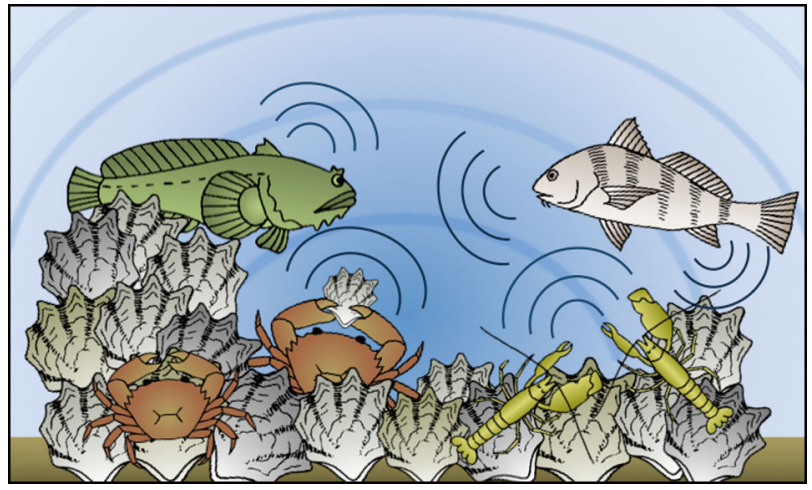

Sound-producing organisms create a distinct oyster reef soundscape. Hear a sample at www.int-res.com/abstracts/ meps/v505/feature/

Illustration: Tanya L. Rogers

\section{INTRODUCTION}

The ambient acoustic environment, or soundscape, represents a fundamental, yet understudied element of ecosystems (Cotter 2008, Pijanowski et al. 2011). Soundscape patterns have the potential to provide meaningful sensory information to animals that reflects the changing biological and physical characteristics of the environment (Rogers \& Cox 1988, Cotter 2008). Soundscapes are ecologically relevant in all environments, and because of the efficiency of sound transmission in the oceans, undersea soundscapes are likely to be especially important to marine ecological processes (Cotter 2008). Compared to other sources of sensory signals in the marine realm, such as light and chemicals, sound is present at all depths and operates independently of ocean currents (Kalmijn 1988, Cotter 2008). Soundscapes may be 
instrumental to the structure and function of marine communities, as they can play a role in a variety of ecological processes including navigation, reproduction, defense, territoriality displays, foraging, and in larval settlement and habitat selection (e.g. Cato et al. 2005, Simpson et al. 2005, Montgomery et al. 2006, Slabbekoorn \& Bouton 2008, Lillis et al. 2013).

Underwater soundscapes comprise a variety of abiotic and biotic acoustic sources. Much of the ambient sound in the sea is caused by non-biological sources that can exhibit high spatial and temporal variation such as meteorological and geological activity. In shallow water, the soundscape is particularly affected by surface conditions driven by wind and waves, with sound transmission influenced by the structure and bathymetry of the seabed (Urick 1984). Sounds produced by the presence and activity of fish, mammals, and invertebrates vary across a range of spatial and temporal scales (Cato 1978, 1980, 1993, McCauley \& Cato 2000, Radford et al. 2008b). For example, snapping shrimp (Alpheus and Synalpheus spp.) are a dominant source of sound energy in many temperate, sub-tropical, and tropical coastal habitats globally (Johnson et al. 1947, Knowlton \& Moulton 1963, Urick 1984), producing a loud 'pop' via a cavitation bubble that forms from rapid claw closure (Versluis et al. 2000). Other common biological components of the soundscape include transient sounds produced by marine animals during matefinding, navigation, and foraging activities, as well as sounds used for defense and intraspecific communication (e.g. Luczkovich \& Sprague 2002, Amorim et al. 2006, Fay et al. 2008, Patek et al. 2009). Moreover, sounds may be generated indirectly via animal activity, such as the movements of schooling fish (Moulton 1960), closing of shells by bivalves (Di Iorio et al. 2012), or the scraping of algae from rocks by feeding urchins (Radford et al. 2008a).

Given that ecological communities are generally habitat-type specific, and that the combination of soniferous species, animal activities (e.g. feeding, swimming), and structure of the habitat creates the ambient sound in a particular location, local soundscapes could be reliable indicators of differences in benthic habitat for settling organisms. In addition to responses to chemical and hydrodynamic cues, receptivity by dispersing larval stages to a changing soundscape could be adaptive during the habitat selection and settlement processes. Investigations of the use of acoustic cues in larval orientation and settlement provide evidence that certain fish, crustacean, and molluscan larvae can detect and respond to the acoustic characteristics associated with their settlement habitats (Simpson et al. 2005, Montgomery et al. 2006, Radford et al. 2007, Stanley et al. 2012). Recent lab and field experiments showed that vessel noise increased settlement rates for a suite of invertebrate phyla (Wilkens et al. 2012, J. Stanley pers. comm.), and habitat-related sound can influence settlement in oyster larvae (Lillis et al. 2013). However, our understanding of habitat-associated sounds and their spatiotemporal dynamics, especially as they relate to larval dispersal processes, is very limited (Radford et al. 2010, McWilliam \& Hawkins 2013).

Soundscape ecology is an emerging field, and observations of the ambient acoustic environment within many ecologically important marine habitats are nascent. For example, studies have been performed to describe the acoustic patterns of temperate coastal habitats in New Zealand (Radford et al. 2008b, 2010), to compare sound on different tropical coral reefs (Kennedy et al. 2010, Staaterman et al. 2013), and to measure spatial heterogeneity in a temperate inshore marine environment (McWilliam \& Hawkins 2013). Defining a suite of representative acoustic parameters based on what have typically been shortduration (minutes), unrepeated recordings, however, remains challenging, and few studies have used data collected simultaneously across sites when making spatial comparisons. Since soundscapes are the product of a variety of biological and physical sources that can be highly dynamic in space and time, more comprehensive characterizations must be carried out to assess inter- and intra-habitat sound patterns at scales relevant to ecological processes.

Oyster reef habitats serve an important role in estuarine environments by acting as structured biogenic habitat that provides shelter and feeding opportunities for a myriad of resident and transient species (Boudreaux et al. 2006). Based on physical structure, as well as abundance and diversity of sound-producing organisms, oyster reefs can differ in their acoustic characteristics compared to other unstructured soft-bottom estuarine habitats and thus potentially offer an acoustic signal to reef-seeking organisms (Lillis et al. 2013). The objective of this study was to investigate habitat-related spatial patterns in an estuarine soundscape by comparing the acoustic dynamics of adjacent oyster reef and off-reef soft-bottom areas within the context of habitatassociated sound as a larval settlement cue for estuarine organisms. To describe the spatial heterogeneity in acoustic characteristics and to determine whether ambient sound reliably reflects differences in benthic settlement habitat, comprehensive meas- 
urements of habitat-related sound were collected for 3 estuarine sites over 2 sampling years.

\section{MATERIALS AND METHODS}

Two complimentary sampling approaches tested the general hypothesis that oyster reef habitats differ in their acoustic characteristics (i.e. sound pressure level and frequency composition) compared to unstructured soft-bottom habitats. The first approach concurrently measured reef and off-reef acoustic characteristics within a site at monthly intervals for 4 mo throughout the larval settlement season at 2 oyster reserves, and the second approach measured the gradient in sound with distance from reefs at 2 sites each in 2 sampling years.

\section{Study site}

This study was carried out in Pamlico Sound, North Carolina, a vast lagoonal-type estuary located in the southeastern USA (Fig. 1). The shallow waters of Pamlico Sound are separated from the Atlantic Ocean by a group of barrier islands and contain a variety of productive nursery and adult habitats for numerous finfish and invertebrate species (Pietrafesa et al. 1986, Etherington \& Eggleston 2000, Pierson \& Eggleston 2014). Wind-driven currents and freshwater input dominate circulation in Pamlico Sound (Pietrafesa \& Janowitz 1988, Xie \& Pietrafesa 1999, Luettich et al. 2002), with little strong vertical shear flows (Haase et al. 2012). Wind forcing is highly variable in this system and can change direction and speed every few hours to days, with current velocities responding rapidly to winds (Xie \& Eggleston 1999, Haase et al. 2012). However, dominant wind and current patterns do persist seasonally along the NE-SW axis of the estuary, with prevailing southwesterly winds in the latespring/summer and northeasterly winds in the late-summer/fall (Xie \& Eggleston 1999).

To aid in the recovery of severely reduced oyster populations in Pamlico Sound, in 1996 the North Carolina Division of Marine Fisheries began to create sub-tidal oyster broodstock reserves, in which oyster harvesting and the use of bottomdisturbing fishing gear are prohibited. Ten oyster reserves have been constructed throughout Pamlico Sound and range in size from 0.03 to $0.19 \mathrm{~km}^{2}$, with inter-reserve distances of 20 to $105 \mathrm{~km}$. Within reserve boundaries, high-relief mounds $(\sim 2 \mathrm{~m}$ off bottom, $\sim 10 \mathrm{~m}$ in diameter) consisting of $\sim 0.5 \mathrm{~m}$ diameter pieces of limestone marl provide larval settlement substrate for the development of oyster reefs. Construction of three oyster reserves was supplemented by oyster and clam shells. All restored oyster reserves now harbor productive reef communities, including high densities of oysters and numerous resident finfish and invertebrates (Rindone \& Eggleston 2011, Puckett \& Eggleston 2012, Pierson \& Eggleston 2014). Oyster reefs within reserves are typically the only 3-dimensional substrate on an otherwise relatively featureless bottom (sand, mud, or silt). Acoustic characteristics of oyster reefs and adjacent soft-bottom habitats were compared within 3 reserve sites (Fig. 1: West Bay, Clam Shoal, and Crab Hole) that spanned the length of Pamlico Sound and encompassed a range of reef characteristics (physical and biological) such as reserve size, construction date, wave energy exposure (e.g. embayment versus shoal), and oyster density.

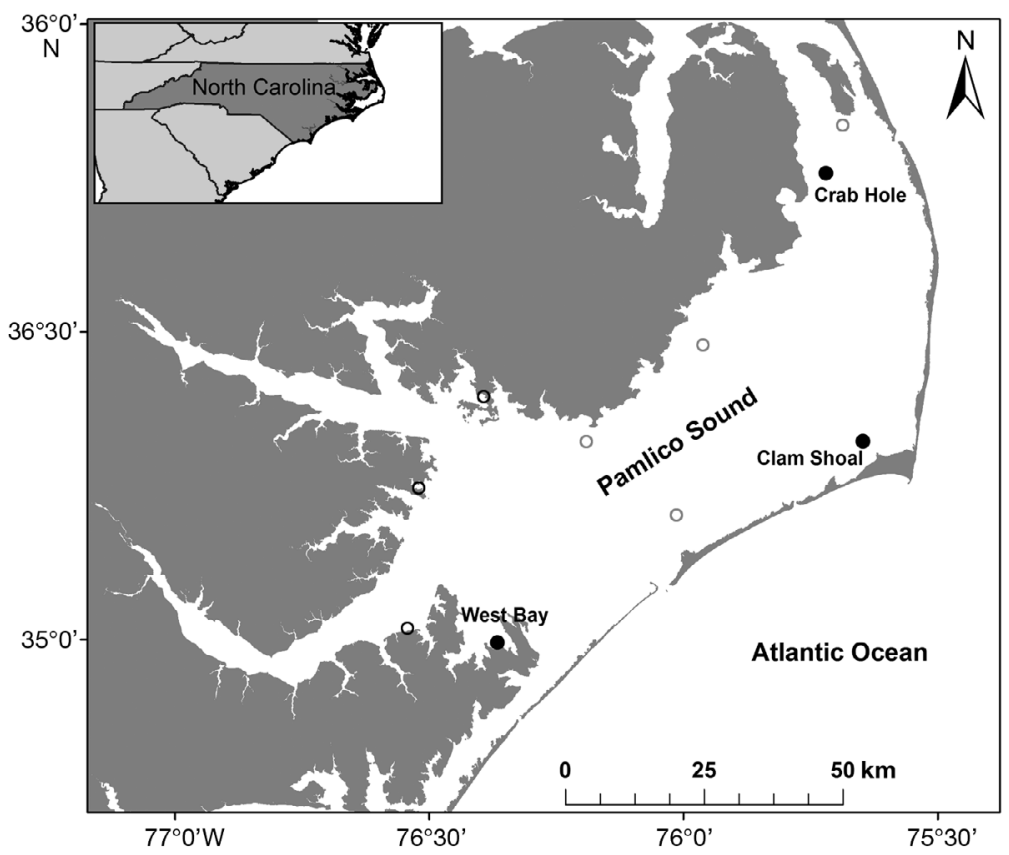

Fig. 1. Oyster reserve sites in Pamlico Sound, North Carolina (USA), where acoustic recordings were made (black circles), as well as locations of additional oyster reserves (open circles). Reserves sampled were West Bay (WB), Clam Shoal (CS), and Crab Hole (CH). Repeated concurrent reef/off-reef recording pairs were collected at WB and $\mathrm{CH}$ in 2010; recording transect surveys were conducted at WB and CS in 2010 and 2011 


\section{Concurrent reef and off-reef acoustic recordings}

Acoustic sampling. To compare the acoustic characteristics of oyster reef and off-reef soft-bottom habitats, the ambient soundscape was simultaneously measured at an oyster reserve ('reef') and nearby soft-sediment ('off-reef') site during monthly sampling events in summer and fall of 2010. This sampling was conducted at 2 locations $100 \mathrm{~km}$ apart in Pamlico Sound (Fig. 1: West Bay, Crab Hole), once each month for July to October during the new moon period ( $\pm 3 \mathrm{~d}$ from the astronomical event) to minimize potential lunar effects on monthly comparisons. Reef recordings were made within reserve boundaries at stations located $\sim 20 \mathrm{~m}$ from structured oyster bottom. Off-reef stations were located in soft-bottom areas at ranges of 1 to $2 \mathrm{~km}$ from the reef and selected to closely match the associated reef depth. Recordings began just prior to sunset and lasted between 3 and $5 \mathrm{~h}$ (dependent on recorder battery life), capturing the dusk and early evening soundscape. Dusk-time recording was chosen for several reasons: (1) to minimize the contribution of boat sound and other anthropogenic influences, (2) to avoid confounding effects of potential diel variation in acoustic patterns (McCauley \& Cato 2000, Radford et al. 2008b), since the primary aim of the current study was to capture habitat-scale spatial variation rather than temporal variation in acoustic characteristics, and (3) because dusk is typically a bio-acoustically active period (Radford et al. 2010). Hydrophone recording systems consisted of a calibrated omnidirectional SQ-26-08 hydrophone (Sensor Technology; flat frequency response $0.1-30 \mathrm{kHz}$, sensitivity $-169 \mathrm{~dB}$ re $1 \mathrm{~V} / \mu \mathrm{Pa}$ ) anchored $0.5 \mathrm{~m}$ off-bottom, and an M-Audio Microtrack II digital acoustic recorder (48 kHz sampling rate, 24 bit) with external battery pack contained in a surface float. The recorders were calibrated by recording pure tone sine waves of multiple frequencies produced by a signal generator (Simpson Electric Function Generator 420).

Data analysis. Prior to any analysis, spectrograms (visual representations of spectra of frequencies over the length of a sound recording) were inspected to ensure the absence of any substantial anthropogenic inputs (e.g. boat noise). For both habitat types and for each month of sampling at each site, a concurrent time window spanning $1 \mathrm{~h}$ past sunset was identified as being free of discernable anthropogenic sounds and used for subsequent analyses. Acoustic spectra (the sound pressure expressed as a function of frequency) were used to compare the frequency composition of the hour-long reef/off-reef recording pairs.
To estimate the central tendency and variability of the acoustic spectra for each hour-long recording, the median value and empirical $68 \%$ quantile ranges were calculated from a set of non-overlapping $10 \mathrm{~s}$ duration windows.

These hour-long recordings were then analyzed by filtering the sound to compute the root mean square (rms) sound pressure levels in low (0.1-2 kHz) and high $(2-23 \mathrm{kHz})$ frequency bands. These frequency bands were selected based on initial examination of spectrograms and acoustic spectra, which exhibited differences between habitat soundscapes that naturally divided into these frequency ranges, and also because these 2 frequency ranges are generally associated with different acoustic sources, with sound in the $0.1-2 \mathrm{kHz}$ band dominated by fish vocalizations, as well as wind and wave-derived sources (Urick 1984), and the $2-23 \mathrm{kHz}$ band dominated by snapping shrimp and invertebrate-generated sounds (Au \& Banks 1998).

Using these hour-long concurrent time series, we also characterized the acoustic diversity of habitats by computing an acoustic entropy index $(H)$ and spectral dissimilarity index $\left(D_{f}\right)$ (Sueur et al. 2008). Measures of acoustic diversity can reveal ecologically meaningful information from complex signals and, in this study, aid in detecting acoustic differences between reef and off-reef habitats. These acoustic diversity indices were modeled after the Shannon index, a widely used ecological index for species diversity (Lande 1996, Sueur et al. 2008). The acoustic entropy index $(H)$ is a measure of the acoustic diversity in a recording (between 0 and 1) that increases with the number of spectral bands and amplitude modulations present, so that higher $H$ values indicate a greater number of acoustic sources (Sueur et al. 2008). The spectral dissimilarity index $\left(D_{f}\right)$ describes the difference in spectra between a pair of recordings, such that $D_{f}$ increases with increasing spectral dissimilarity (Sueur et al. 2008, Gasc et al. 2013).

An $H$-value was calculated for each reef and offreef recording as the product of both temporal and spectral entropies $\left(H_{t} \times H_{f}\right.$, with $H$ between 0 and 1$)$, using the following equations:

$$
\begin{aligned}
& H_{t}=-\sum_{t=1}^{n} A(t) \times \log _{2} A(t) \times \log _{2}(n)^{-1} \\
& H_{f}=-\sum_{f=1}^{N} S(f) \times \log _{2} S(f) \times \log _{2}(N)^{-1}
\end{aligned}
$$

where $A(t)$ is the probability mass function of the amplitude envelope, and $S(f)$ is the probability mass 
function of the acoustic spectrum. For each hour-long recording, $H_{t}$ was calculated within a series of nonoverlapping $30 \mathrm{~s}$ duration windows $\left(\mathrm{n}=1.44 \times 10^{6}\right.$ points), following the time window duration adopted by Sueur et al. (2008). $H_{f}$ was computed within these same windows, using the mean spectra derived from the short time Fourier transform (STFT) of 512 point data segments (as in Sueur et al. 2008), giving a frequency resolution of $93.75 \mathrm{~Hz}(\mathrm{~N}=256)$. This produced a set of $H$ index values for each of the 8 concurrent reef/off-reef recording pairs $(2$ sites $\times 4$ sampling months).

One challenge in the statistical analysis of these $H$-index time series is the potential for serial correlations. To address this effect, we down-sampled the $H$ data using every third data point. Using these down-sampled data, the non-parametric KolmogorovSmirnov test (K-S test; Stephens 1974) was applied to test the hypothesis that the distribution of $H$-values from each pair of oyster reef and off-reef habitats was drawn from the same underlying continuous population. We also estimated the median $H$-value and its standard error uncertainty using a nonparametric bootstrap procedure. This factor-of-three downsampling scheme was selected based on the lack of correlation observed in $H$-index lag plots, although other down-sampling permutations (using factors of 1 to 6 ) produced nearly identical statistical results.

The spectral dissimilarity index $\left(D_{f}\right)$ was used as an additional measure to quantify the spectral differences of each concurrent recording pair as follows:

$$
D_{f}=\frac{1}{2} \sum_{f=1}^{N}\left|S_{1}(f)-S_{2}(f)\right|
$$

where $S_{1}(f)$ and $S_{2}(f)$ refer to the spectral probability mass function of the reef and off-reef habitats, again calculated within a series of $30 \mathrm{~s}$ duration windows using an average STFT of 512 point data segments, giving a frequency resolution of $93.75 \mathrm{~Hz}(\mathrm{~N}=256)$. For each on- and off-reef recording pair, the median $D_{f}$ value and its standard error uncertainty were calculated using a nonparametric bootstrap procedure. The spectral dissimilarity present between the 2 habitat soundscapes can range from 0 to 1 , with a 0 -value indicating signals of identical spectral composition.

\section{Oyster reef sound propagation}

Acoustic sampling. To examine how acoustic characteristics changed with distance from oyster reef habitats (i.e. how localized are habitat-associated sounds?), passive sound propagation measurements were conducted at 2 Pamlico Sound oyster reserve sites (Fig. 1; West Bay and Clam Shoal) using an approach similar to a study of propagation from a rocky reef (Radford et al. 2011). Short-term recordings of ambient underwater sound were made at increasing distance from the oyster reserves in September 2010, and repeated in June 2011 with an expanded distance range. Two acoustic recording systems with hydrophones mounted $0.5 \mathrm{~m}$ off the seafloor (specifications as described in 'Concurrent reef and off-reef acoustic recordings' above) were used for each propagation survey: (1) the first unit was placed within the reserve area ( 20 to $30 \mathrm{~m}$ from oyster reef structure) and held stationary for the duration of the survey (as a reference for any temporal changes in reef sound during off-reef measurements) and (2) a second unit was used to make 5 to 10 min recordings at increasing distances from the reserve (transects in 2010: 100, 250, 500, $1000 \mathrm{~m}$; transects in 2011: 100, 250, 500, 750, 1000, 1500, 2000 $\mathrm{m})$. The water depth remained largely constant (3-4 $\mathrm{m})$ over these distances, and the bottom type was consistently fine sand/silt. During recordings the boat was moved $\sim 1 \mathrm{~km}$ from the recorder and the motor was shut off. The direction of the recording transect at each reserve was determined based on the bathymetry of the surrounding area, to best allow for measurements at distances up to $2 \mathrm{~km}$, and also, if possible, to reflect the prevailing current direction from which larval delivery would occur during the summer settlement season. Within each site, this direction remained the same for the 2010 and 2011 sampling events. The passive propagation surveys were completed over $\sim 1 \mathrm{~h}$ periods during morning or afternoon, outside of periods when a temporal shift in biological sound production would be expected (i.e. dawn or dusk; Radford et al. 2008b).

Data analysis. Acoustic waveforms and spectrograms were visually inspected to remove transient anthropogenic noise such as boat motors, and the simultaneous recordings (from stationary on-reef station and a given off-reef station) were truncated to be the same time period as the recordings made at distance from the reef, leaving between 3 and $6 \mathrm{~min}$ of recording to analyze for each distance recording and corresponding reef reference recording.

To compare the soundscape characteristics at increasing distance from the reefs, acoustic spectra were generated for each recording. Additionally, the relationship between sound pressure level and distance from reef was examined by computing the rms sound pressure level $(\mathrm{dB}$ re $1 \mu \mathrm{Pa})$ at increasing distance from reefs within $0.1-2 \mathrm{kHz}$ and $2-23 \mathrm{kHz}$ 
frequency bands identified during the concurrent recordings. Following the approach used for the longer-term recordings, the median spectrum and sound pressure levels, as well as their empirical $68 \%$ quantile ranges, were calculated based on the analysis of non-overlapping 1 s duration windows spanning the recordings. These estimates were made for both the transect recordings and the concurrent onreef (reference hydrophone) recordings.

The received sound pressure levels ( $\mathrm{RL}$ in $\mathrm{dB}$ re $1 \mu \mathrm{Pa}$ ) at varying ranges (R) were then used to calculate the transmission loss coefficient $\left(C_{\mathrm{TL}}\right)$ and estimate the effective source level at a reference distance of $1 \mathrm{~m}$ (SL in dB re $1 \mu \mathrm{Pa} @ 1 \mathrm{~m})$, using the relationship $\mathrm{RL}=\mathrm{SL}-C_{\mathrm{TL}} \times \log _{10}(\mathrm{R})$. For a linear (leastsquared) regression of decibel RL data versus $\log _{10}(R)$, the $y$-intercept term provides an estimate of the effective SL and the slope represents the term $C_{\mathrm{TL}}$. The transmission loss coefficient reflects the manner of sound spreading and can be compared with theoretical values for cylindrical $\left(C_{\mathrm{TL}}=10\right)$ and spherical $\left(C_{\mathrm{TL}}=20\right)$ spreading (Urick 1983). Since the reefs are not a point source, this relationship is not expected to hold at ranges much less than the dimensions of the reef (e.g. Radford et al. 2011). We therefore limited our regression analysis to ranges $>50 \mathrm{~m}$ from the reef boundary. We also limited our regression analysis to measurements made at ranges $<1000 \mathrm{~m}$ from the edge of the reef. Beyond this range (data available in 2011 only), recordings showed nearly constant rms sound pressure levels that represent the ambient offreef sound field of the estuary.

\section{RESULTS}

\section{Concurrent reef and off-reef acoustic recordings}

The reef sounds recorded at each site had visibly different spectral characteristics compared to the simultaneously recorded off-reef sounds (Fig. 2). In contrast to the off-reef habitat, reef acoustic spectra were characterized by more sound contribution above $1.5-2 \mathrm{kHz}$, the frequency range commonly dominated by snapping shrimp sounds (Everest 1948, Ferguson \& Cleary 2001). This pattern was more pronounced and consistent across months at the West Bay site, while at Crab Hole the differences between reef and off-reef were present, yet less prominent, particularly during the October sampling event (Fig. 2).

Spectrograms demonstrate differences in spectral and temporal composition for reef and off-reef recordings at each site and show that a high level of broadband, short-duration snapping shrimp sounds dominated the oyster reef soundscapes (Fig. 3). Although the West Bay reef habitat had a higher overall sound level compared to Crab Hole, the pattern of elevated sound at higher frequencies on reefs versus off-reefs was apparent for both sites. A comparison of the sound pressure levels within the lower and higher frequency bands further confirms that the acoustic differences between the habitats were present in the higher frequency range (Fig. 4). In all months sampled and at both sites, this frequency range contained higher sound levels in reef recordings compared to the off-reef recordings, whereas the lower frequency band does not show a difference between the habitat types (Fig. 4; overlapping confidence intervals).

All simultaneous reef/off-reef recording pairs had significant differences in acoustic entropy (Fig. 5, Table 1; K-S tests, $\mathrm{p}<0.01)$. For all concurrent recordings, the acoustic entropy was higher on the oyster reef compared to the adjacent off-reef area; however, this effect was smaller and more variable at the Crab Hole site than at West Bay. Moreover, the acoustic entropy index was higher at the West Bay reef compared to Crab Hole, with the on-reef $H$-index values observed at West Bay being less variable across the 4 mo of sampling. Differences in the $H$-index were driven by the spectral entropies $\left(H_{f}\right)$; temporal entropies $\left(H_{t}\right)$ did not differ significantly between recording pairs. An acoustic spectral dissimilarity index $\left(D_{f}\right)$ was calculated for each reef/off-reef recording pair, and values ranging from 0.094 to 0.635 (identical signals would produce a null $D_{f}$ value, Sueur et al. 2008) indicate that the 2 habitat types were dissimilar in their soundscape composition, again with relatively greater reef/off-reef differences at the West Bay site compared to Crab Hole (Table 1).

\section{Oyster reef sound propagation}

Acoustic spectra for recordings collected during the propagation surveys generally showed similar acoustic patterns to the concurrent stationary hydrophone recordings described above. Reef and nearreef sites were characterized by broadband energy when compared to the most distant off-reef recordings $(1-2 \mathrm{~km})$, for which acoustic energy was relatively reduced at frequencies above $\sim 1.5-2 \mathrm{kHz}$ (Fig. 6). All reef and near-reef recordings at both sites showed a spectral peak in the 200-300 Hz frequency band, and at West Bay an additional peak was detected in the 450-600 Hz range (Figs. 6 \& 7). These 

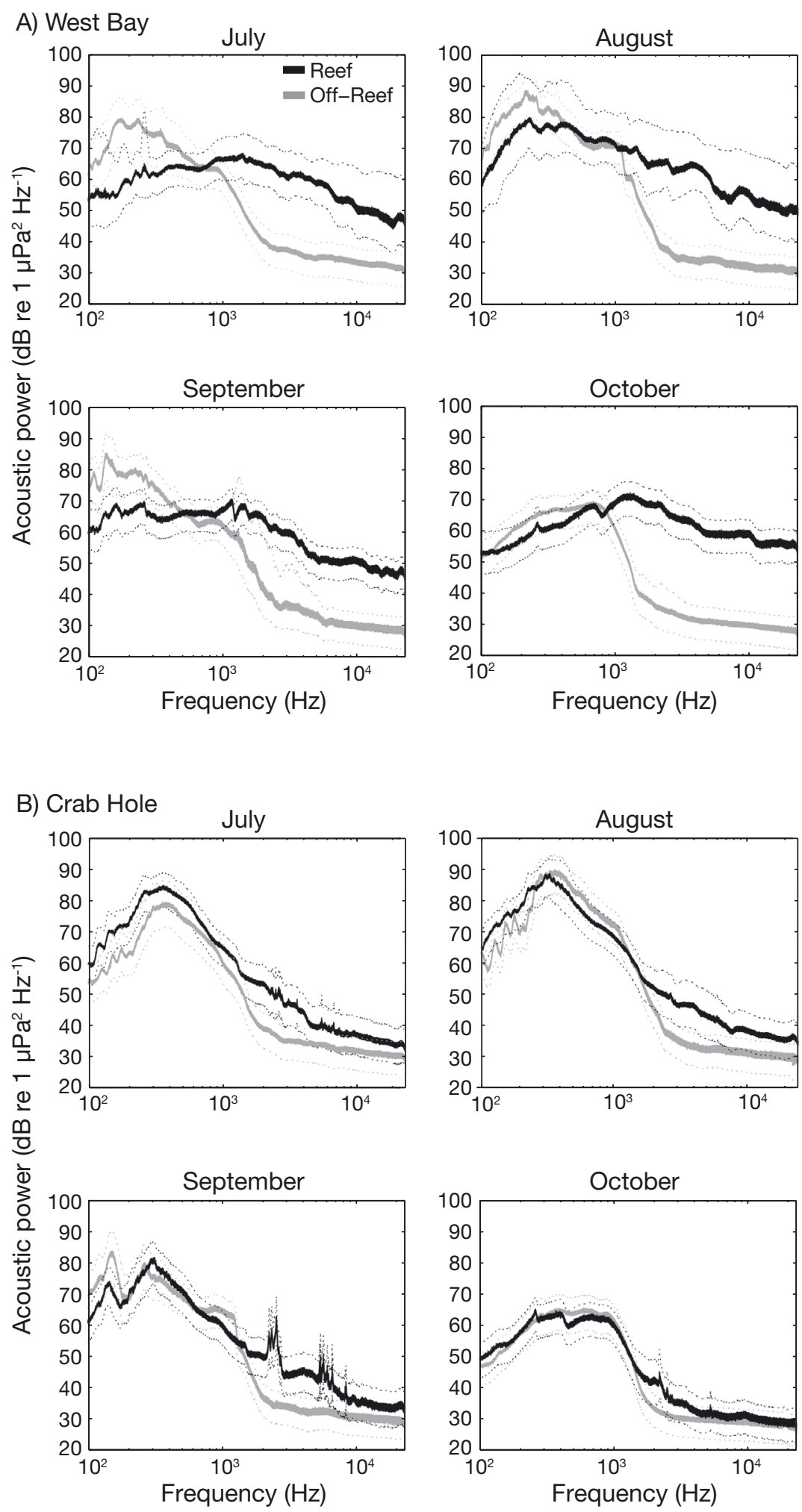

Fig. 2. Acoustic spectra for hour-long simultaneous reef and off-reef sound recordings collected monthly on the new moon at (A) West Bay and (B) Crab Hole. Solid lines represent the median spectra for each hour-long sample, and dashed lines represent the spectral variability (68\% quantile range) determined from a series of non-overlapping $10 \mathrm{~s}$ duration windows peaks were examined in the recordings and identified, based on aural and spectral analysis, as fish calls from the oyster toadfish Opsanus tau (Fine 1978, Fine \& Thorson 2008).

Some notable differences were observed during the 2 sampling years. During the September 2010 recordings, at both sites the sound level in the $0.1-1.5 \mathrm{kHz}$ band remained elevated as the hydrophone was moved up to $1 \mathrm{~km}$ away from the reefs, whereas the sound level above $\sim 1.5 \mathrm{kHz}$ decreased by $\sim 15$ to $20 \mathrm{~dB}$ at a range of 250 to $500 \mathrm{~m}$ from the reefs (Fig. 6A,B). During the June 2011 recordings at West Bay, the sound levels at all measured frequencies decreased $\sim 15$ to $20 \mathrm{~dB}$ within 250 to $500 \mathrm{~m}$ from the reefs (Figs. 6C \& 7) and continued to diminish with distance from the reef. At the Clam Shoal site, following an initial broadband decrease with range, sound levels in the $0.3-1 \mathrm{kHz}$ frequency band increased again for recordings at the farthest distances (1500 and $2000 \mathrm{~m}_{\text {; Fig. 6D). }}$

During the off-reef surveys at West Bay (2010 and 2011) and Clam Shoal (2011), the sound field on the reef was measured using a continuously recording fixed hydrophone. A recorder malfunction prevented equivalent data from being collected at Clam Shoal in 2010. The available data, however, show that the median spectral content and sound levels associated with each reef site remained consistent (to within $\pm 1-2 \mathrm{~dB}$ ) throughout the surveys, each of which took approximately $1 \mathrm{~h}$ to complete. For example, Fig. 7 shows the acoustic spectra from each transect recording made at West Bay (2011) plotted with the spectra of a concurrent recording made on the reef. The stability of the on-reef soundscape at these time scales indicates that the changes in spectral composition and amplitude observed off-reef do not reflect temporal variability, but rather a spatial pattern moving away from the reef habitat, which functions as an acoustic source. 


\section{A) West Bay}

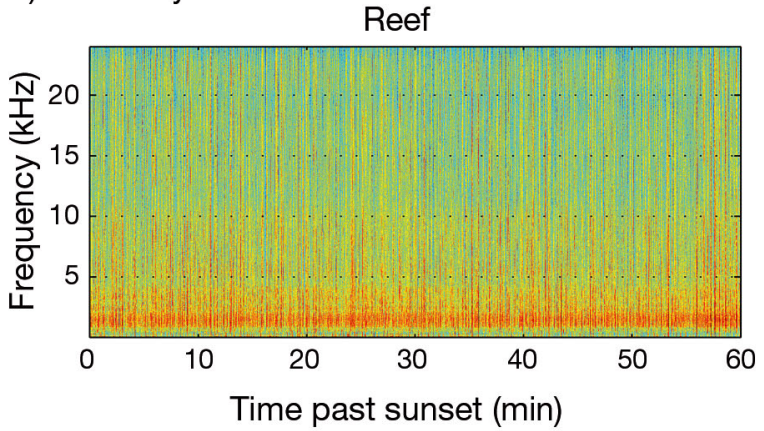

\section{B) Crab Hole}

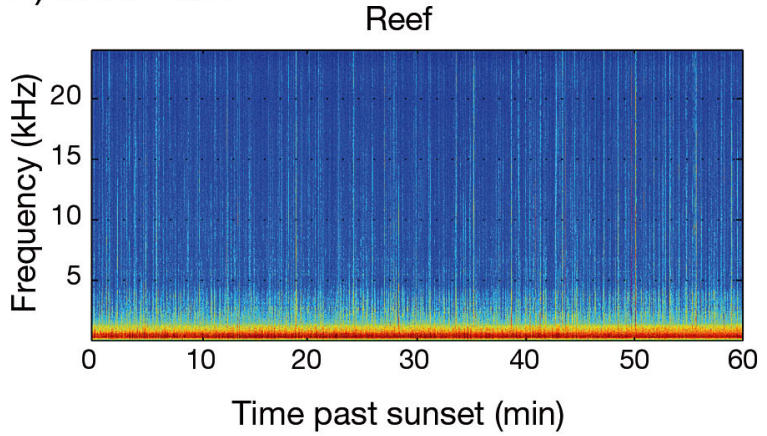

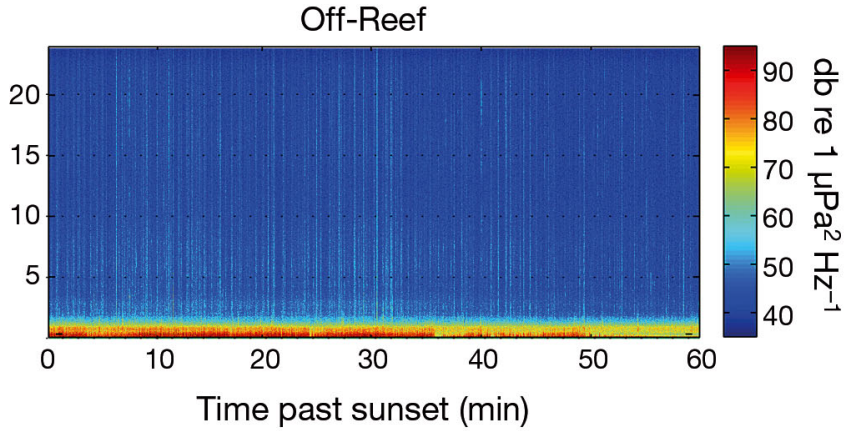

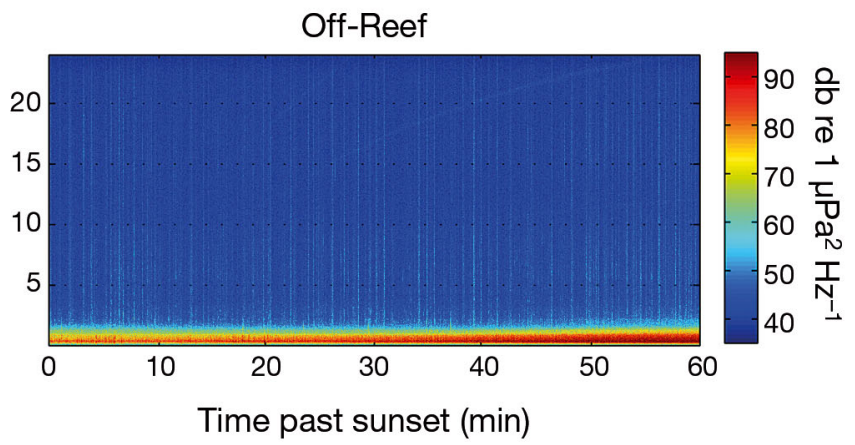

Fig. 3. Spectrograms for August hour-long recordings collected simultaneously in reef and off-reef habitat at (A) West Bay and (B) Crab Hole. Spectrograms were produced using $0.5 \mathrm{~s}$ windows with $25 \%$ overlap

A) West Bay

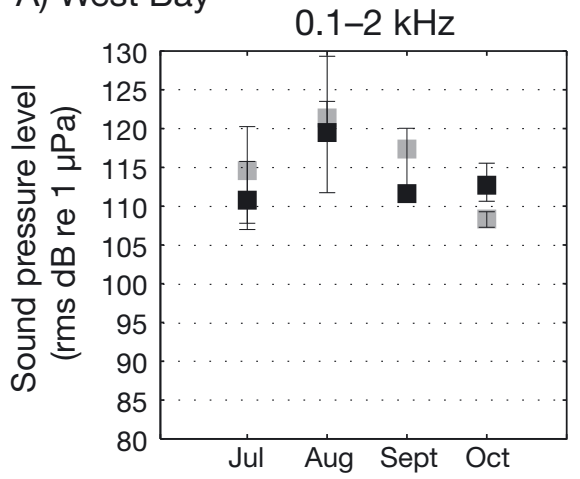

B) Crab Hole

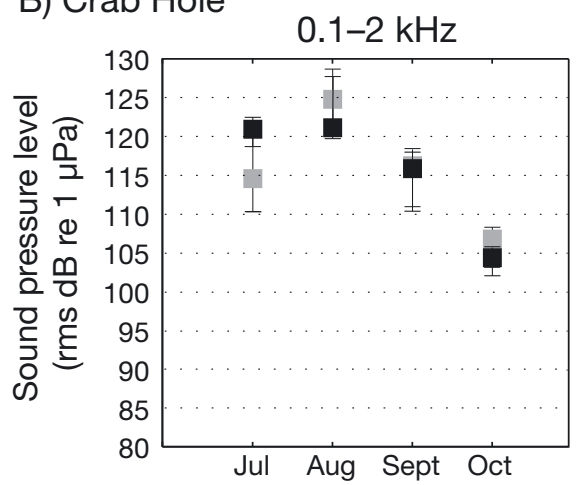

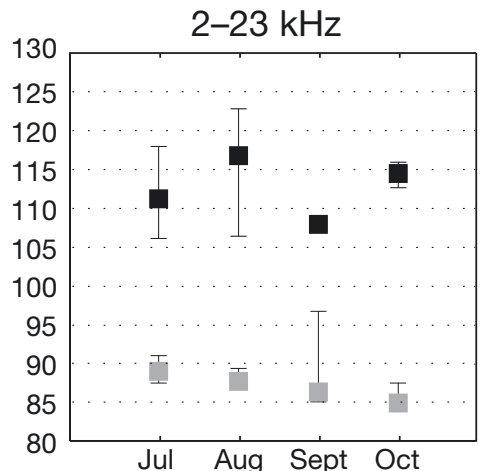

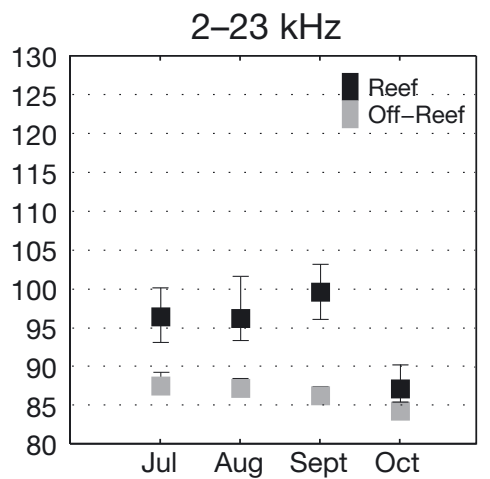

Fig. 4. Comparison of reef and off-reef root mean square (rms) sound pressure levels within lower $(0.1-2 \mathrm{kHz})$ and higher $(2-23 \mathrm{kHz})$ frequency bands for simultaneous recordings made monthly during summer and fall at (A) West Bay and (B) Crab Hole. Squares and error bars show the median and $68 \%$ quantile range determined using a sequence of $10 \mathrm{~s}$ duration, non-overlapping windows spanning a $1 \mathrm{~h}$ recording $(\mathrm{N}=360)$ 

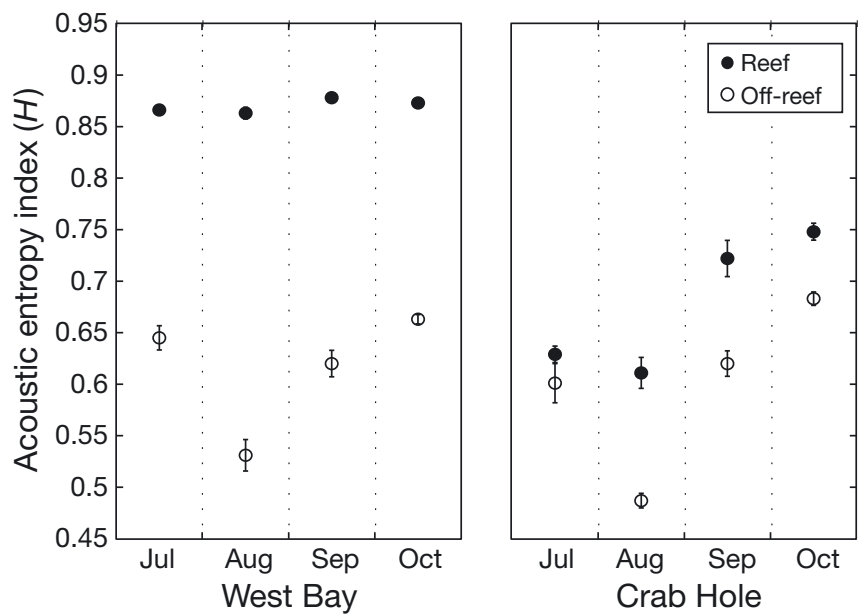

Fig. 5. Comparison of acoustic entropy index $(H)$ values for all reef and off-reef recording pairs during the 2010 habitat comparison recording study. For each site and month, a time series of $H$ was first estimated using a series of 30 s duration, non-overlapping windows spanning a $1 \mathrm{~h}$ recording. These data were then down-sampled by a factor of 3 to minimize possible effects of serial correlation $(\mathrm{N}=40)$. Circles and vertical bars show the median and its standard error uncertainty estimated using a bootstrap procedure

A comparison of the sound pressure levels as a function of distance from the reef for the lower and upper frequency bands highlights the loss of acoustic energy with distance from the reefs, and confirms that the $2-23 \mathrm{kHz}$ frequency band was most distinct to the reef habitat for both sites in both years (Fig. 8). In particular, for the 2010 transects, there was not a substantial decrease in full bandwidth or the $0.1-2 \mathrm{kHz}$ sound levels up to $1 \mathrm{~km}$ from the reefs; yet, sound levels in the $2-23 \mathrm{kHz}$ range did decrease by $\sim 20 \mathrm{~dB}$ (Fig. 8A,B). The 2011 transects, which were conducted over larger distances, found decreases of 15 to $20 \mathrm{~dB}$ in sound levels for full, low-, and highfrequency bands in the first kilometer from the reefs (Fig. 8C,D). At the Clam Shoal reserve, however, there was an increase in the amplitude of the lower frequency band in 2011 at ranges of 1500 and $2000 \mathrm{~m}$ (cf. Fig. 6D). Reference hydrophone data (Fig. 8; red lines) did not show an increase in the on-reef levels during these concurrent recording times.

Because the reefs were the apparent sound source for the higher frequency band, the sound levels in this $2-23 \mathrm{kHz}$ frequency range as a function of distance were used to estimate the transmission loss coefficient $\left(C_{\mathrm{TL}}\right)$ and the effective source level (SL) of the reef signal by fitting a least-squares regression of a logarithmic plot of the received level (RL) versus distance ( $\mathrm{R}$ in meters) (Table 2, Fig. 9). Predicted source levels of the reefs in the $2-23 \mathrm{kHz}$ band are 108.8-120.0 dB re $1 \mu \mathrm{Pa} @ 1 \mathrm{~m}$ (Table 2), which fall within the range of on-reef sound levels measured in this frequency band on the West Bay reef recorded during 2010 (Fig. 4A). Transmission loss coefficients were between 7.6 and 12.1, which brackets the theoretical value of 10 associated with a cylindrical geometric spreading model widely used in ocean acoustics (e.g. Urick 1983). With regard to the propagation of reef sounds, the applicability of this cylindrical spreading loss model at ranges greater than the dimensions of source structure was also shown by Radford et al. (2011), who studied propagation away from a $\sim 600 \mathrm{~m}$ long rocky reef near Taranga Island, north-eastern New Zealand, in water depths of 55 to $70 \mathrm{~m}$.

\section{DISCUSSION}

\section{Habitat-related acoustic characteristics}

Estuarine habitats have been well studied in an ecological context, but to our knowledge this is the first study to consider the ecological significance of habitat-related acoustic features in an estuarine

Table 1. Median acoustic entropy $(H)$ and spectral dissimilarity $\left(D_{f}\right)$ indices for recordings made at dusk in reef and off-reef habitats. All reef/off-reef recording pairs were made concurrently. The null hypothesis that reef/off-reef $H$ values are sampled from the same underlying population can be rejected for each site and month (Kolmogorov-Smirnov tests: $p<0.01$ ). Uncertainties $( \pm$ ) represent the standard error in the median values, as determined using a non-parametric bootstrap procedure

\begin{tabular}{|llccrr|}
\hline Site & Index & July & August & September & October \\
\hline West Bay & Reef $H$ & $0.866 \pm 0.0025$ & $0.863 \pm 0.0056$ & $0.878 \pm 0.0026$ & $0.873 \pm 0.0027$ \\
& Off-reef $H$ & $0.645 \pm 0.0118$ & $0.531 \pm 0.0153$ & $0.620 \pm 0.0128$ & $0.663 \pm 0.0045$ \\
& $D_{f}$ & $0.652 \pm 0.0098$ & $0.607 \pm 0.0032$ & $0.583 \pm 0.0094$ & $0.578 \pm 0.0094$ \\
Crab Hole & Reef $H$ & $0.629 \pm 0.0080$ & $0.611 \pm 0.0150$ & $0.723 \pm 0.0176$ & $0.748 \pm 0.0082$ \\
& Off-reef $H$ & $0.601 \pm 0.0200$ & $0.487 \pm 0.0071$ & $0.620 \pm 0.0124$ & $0.683 \pm 0.0065$ \\
& $D_{f}$ & $0.146 \pm 0.0065$ & $0.084 \pm 0.0020$ & $0.252 \pm 0.0044$ & $0.112 \pm 0.0040$ \\
\hline
\end{tabular}



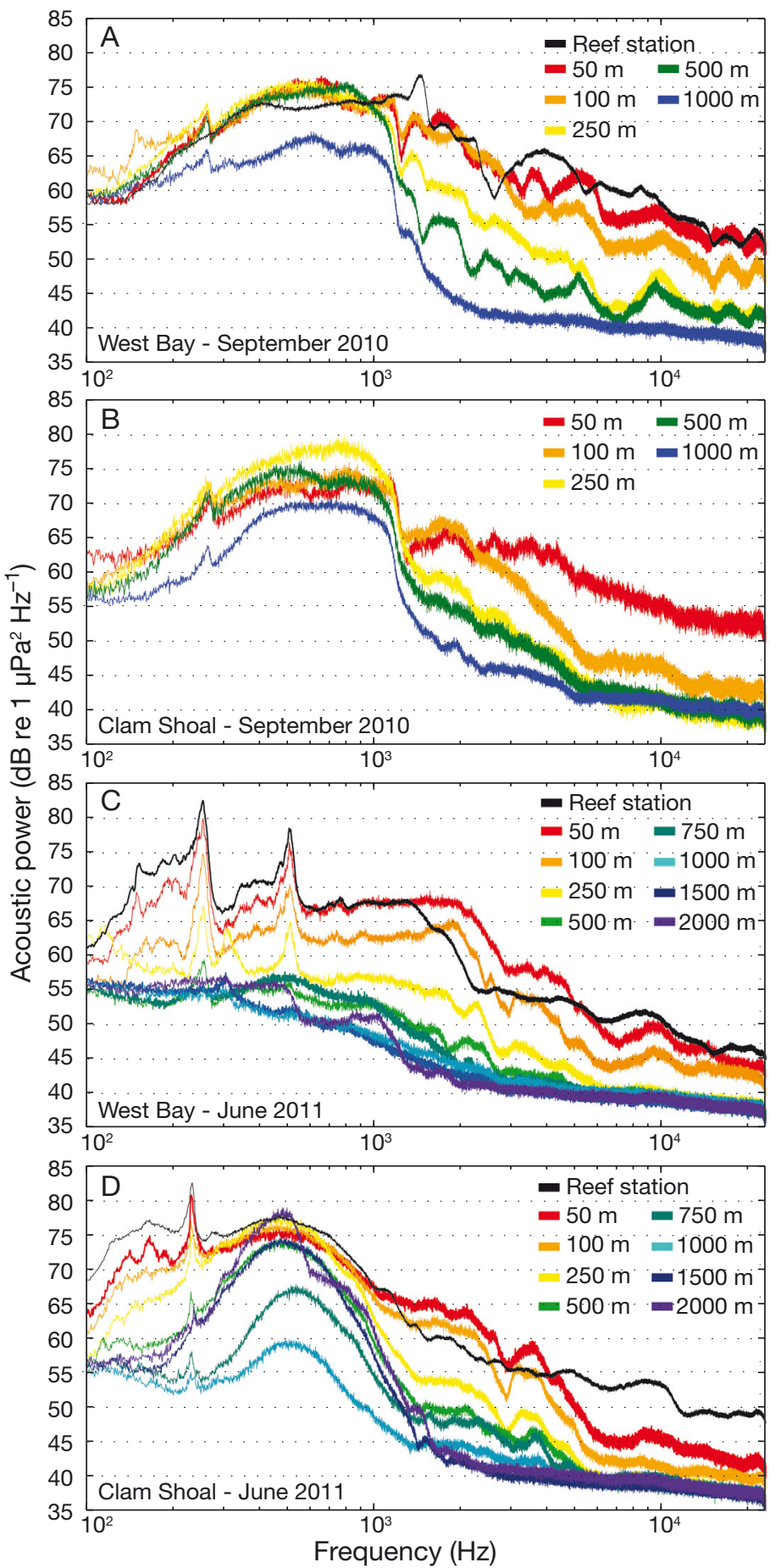

Fig. 6. Power spectra for reef sound propagation surveys at 2 oyster reef sites in Pamlico Sound, North Carolina, showing the spectrum for the reference reef station hydrophone in black (for all time periods when off-reef recordings were collected) and spectra for increasing distances from the reef in progressively cooler colors. West Bay and Clam Shoal oyster reserves were each sampled in (A,B) September 2010 and (C,D) June 2011. A reef reference spectrum is not shown in (B) due to a malfunctioning stationary reef hydrophone during the Clam Shoal survey. Power spectral density was calculated as the median of non-overlapping $1 \mathrm{~s}$ windows for the duration of each recording environment, and to characterize the acoustic differences between sub-tidal oyster reef and off-reef habitats. Comparisons of spectral composition, ambient sound levels, and acoustic diversity indices support the hypothesis that there are significant differences in the acoustic characteristics of reef and off-reef habitats in Pamlico Sound. These differences largely reflect sound production in the frequency bands associated with reef-dwelling organisms such as oyster toadfish and snapping shrimp. The acoustic contribution of such species to the ambient soundscape declined significantly over relatively small distances $(<1 \mathrm{~km})$ from the reef. Moreover, this habitatspecific sound field was maintained throughout the duration of the reef/off-reef sampling (summer and fall), suggesting that acoustic patterns could be a stable indicator of changing benthic habitat type for dispersing larvae and various life history stages of mobile organisms that might use sound as an orientation cue. These data imply that in this shallow, estuarine system it would be most adaptive for reefseeking organisms to respond to soundscape variation in the higher frequency range, or in frequencies associated with species that are endemic to reefs. However, sound detection abilities and behavioral responses to specific frequencies have not been determined for the majority of larval fish or invertebrates, and establishing the biological responses to particular acoustic components of soundscape characterizations such as this represents a key future research direction.

The acoustic entropy index $(H)$ values indicate that reefs may have a higher diversity of sound sources. This result is not unexpected given that oyster bed communities are known to be diverse, productive habitats for a variety of fish and invertebrates that rely on the oyster reef structure for food and shelter (White \& Wilson 1996, Rindone \& Eggleston 2011, Pierson \& Eggleston 2014). Recordings collected for this study clearly show that snapping shrimp are a dominant feature of the oyster reef soundscapes in this region and are a major contributor to the habitat-related acoustic differences we detected (e.g. Fig. 3). In many tropical, subtropical, and temperate regions, the broad spectrum snaps of Alpheus spp. and Synalpheus spp. are known to acoustically dominate structurally complex environments where the snapping shrimp shelter (Knowlton \& Moulton 1963, Au \& Banks 1998, Chitre et al. 2006, 2012, Radford et al. 2010). Because of their acoustic significance to coastal soundscapes and spatial clustering in structured habitats, snapping shrimp could represent a keystone species in sound- 


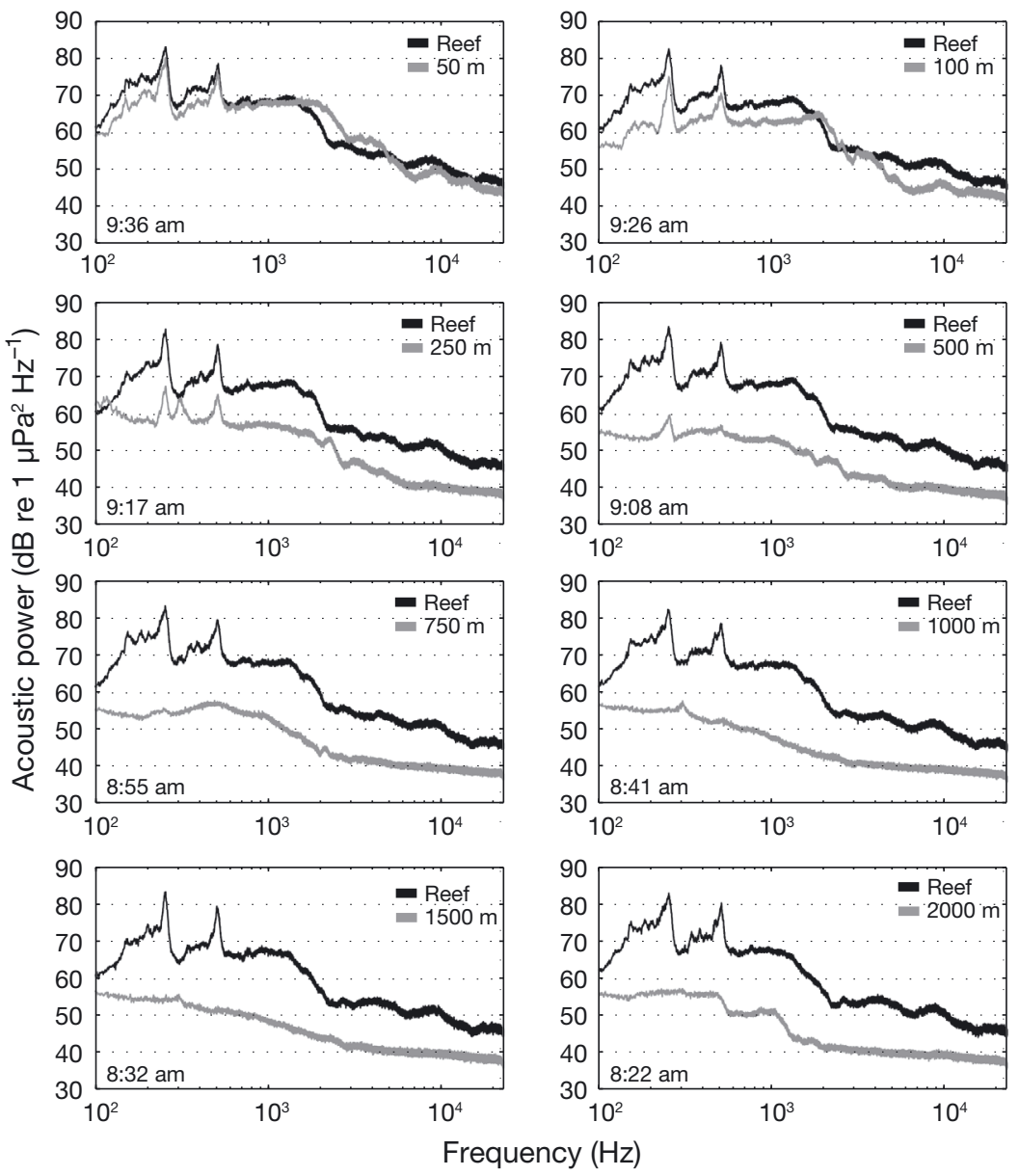

Fig. 7. Acoustic spectra for the West Bay 2011 recording transect, comparing the spectrum for each distance to the concurrent on-reef recording. Power spectral density was calculated as the median of non-overlapping $1 \mathrm{~s}$ duration windows for the entire length of each recording. Start times of recordings (in local time, EST) are indicated on each plot
Atlantic croaker Micropogonias undulatus are 2 to 4 times more abundant on oyster reefs compared to off-reef areas. Oyster toadfish Opsanus tau and croaker spot Leiostomus xanthurus make up a large proportion of the fish assemblage on reefs, but are absent from surrounding soft-bottom habitats (Pierson \& Eggleston 2014). These fishes are known to produce sounds with dominant frequencies ranging from 100 to $1300 \mathrm{~Hz}$, and to exhibit temporal variation in sound production associated with reproductive patterns (Sprague et al. 1998, Ramcharitar et al. 2006, Gannon 2007, Fine \& Thorson 2008, Luczkovich et al. 2008). The influence of soniferous fish on the habitat-related soundscape is demonstrated by the toadfish signal in our reef propagation surveys, where the distinctive toadfish calls are closely associated with the reef environment. Fish sounds clearly are a major component of the estuarine soundscape, and the sounds of certain fish species may define particular habitats. The highly dynamic nature of fish calls and the transience of many soniferous species on reefs, however, suggest that these sounds may not be as consistent a source of sound compared to resident snapping shrimp. Both the reef/off-reef paired recordings and the sound propagation surveys demonstrate the scape ecology, and it may be possible to use snapping shrimp sound as a monitoring tool for habitat type and quality in certain environments (Radford et al. 2010, Chitre et al. 2012, McWilliam \& Hawkins 2013). Despite their potential ecological significance, remarkably little is known about the drivers of snapping shrimp abundance, distribution, and acoustic activity - this will be an important area of future research in soundscape ecology.

Differences in fish assemblages between reef and off-reef habitats represent another influence on soundscape composition and diversity. The oyster reef communities in the reserve sites in Pamlico Sound have higher abundances of sound-producing fish species compared to adjacent soft-bottom areas (Pierson \& Eggleston 2014). Soniferous species such as weakfish Cynoscion regalis, pigfish Orthopristis chrysoptera, silver perch Bairdiella chrysoura, and importance of the higher frequency band in distinguishing the oyster reef soundscape, and this is reinforced by the 2011 Clam Shoal propagation survey, which showed that the lower frequency band was not distinct to the reef habitat. Since this frequency band encompasses sounds produced by aggregations of the sciaenid fishes common in Pamlico Sound environments (Sprague et al. 1998, 2000, Luczkovich et al. 2008), the re-emergence of the low frequency peak in the recordings at 1500 and $2000 \mathrm{~m}$ was likely due to proximity to other sources of fish sounds such as the numerous seagrass beds and shoals in the Clam Shoal area. Because the 2010 survey did not extend to these distances, we cannot assess whether the lower frequency trend detected at Clam Shoal in 2011 was due to a transient event (e.g. school of fish) or more permanent feature (e.g. nearby seagrass bed). 
Full bandwidth

A) West Bay 2010

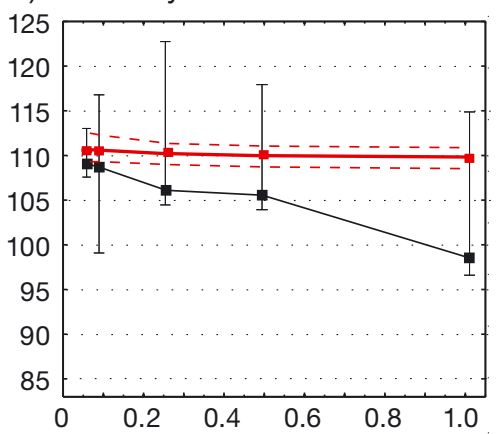

B) Clam Shoal 2010

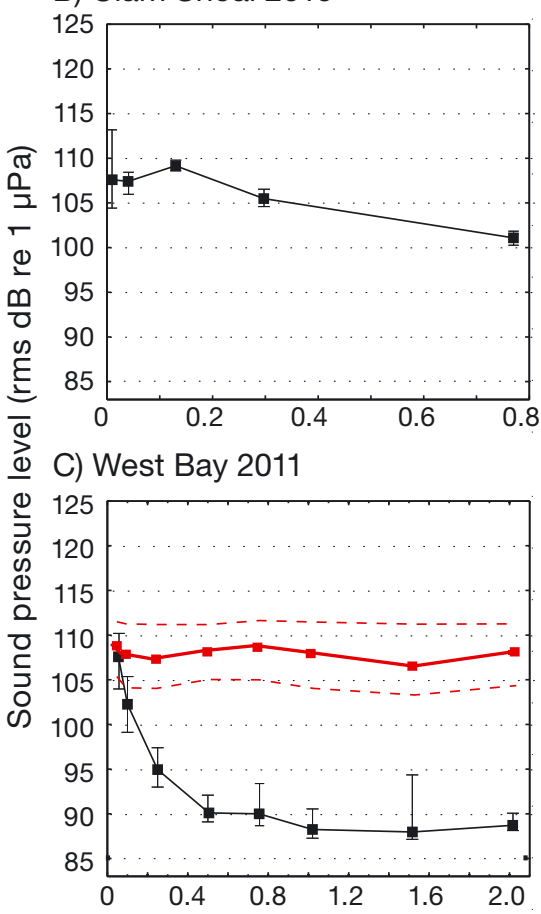

D) Clam Shoal 2011

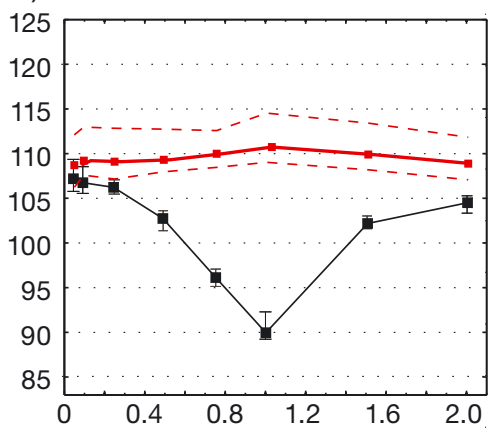

$0.1-2 \mathrm{kHz}$
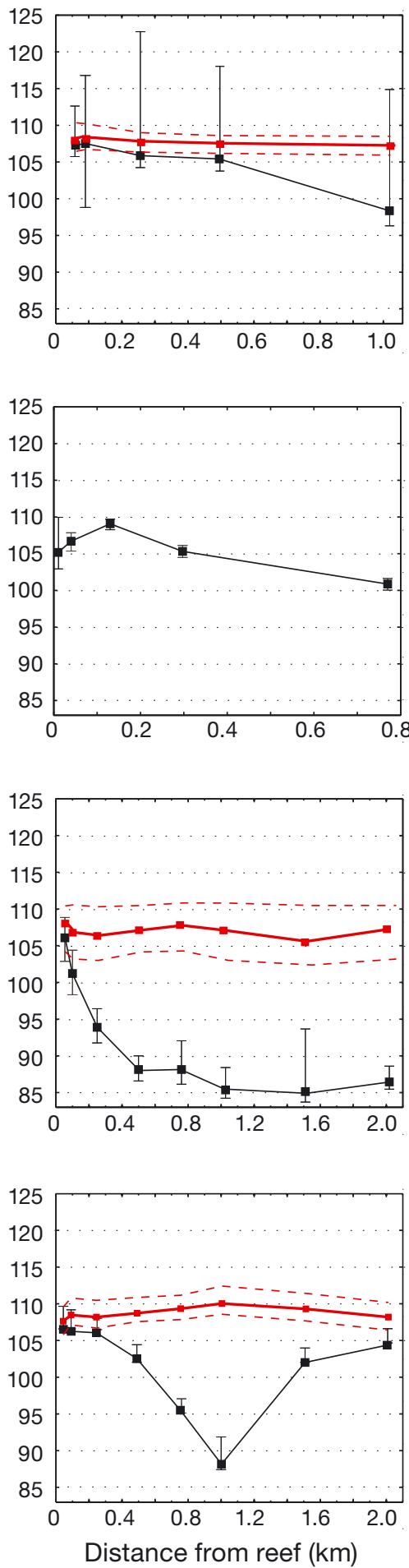

2-23 kHz
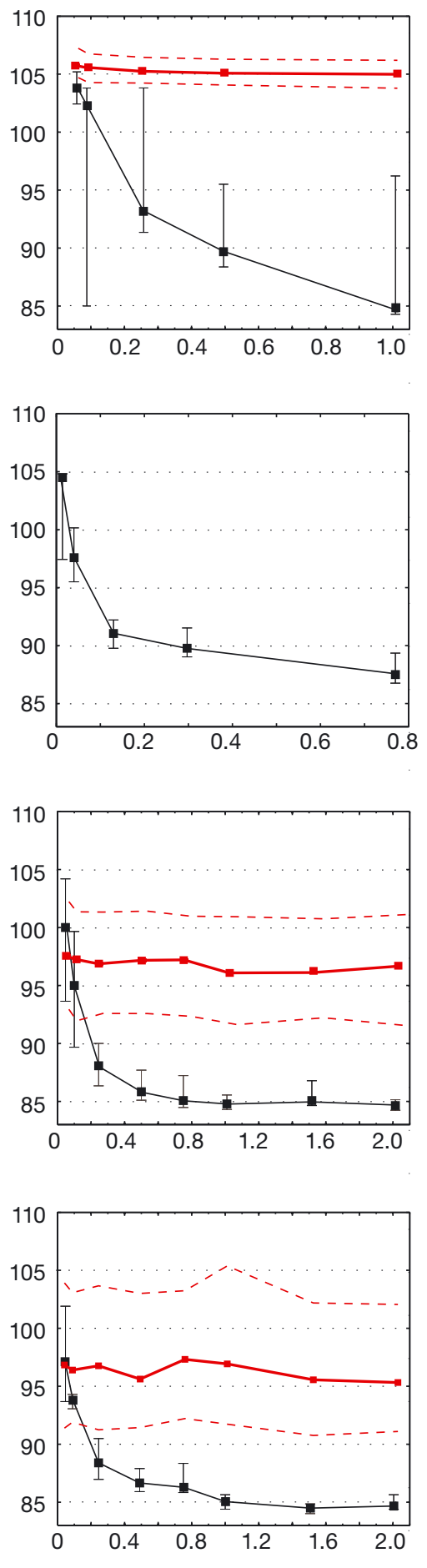

Fig. 8. Sound pressure level with distance from the reefs for full bandwidth, $0.1-2 \mathrm{kHz}$, and $2-23 \mathrm{kHz}$ frequency bands (in black). Black squares and error bars show the median and $68 \%$ quantile ranges determined from using a sequence of $1 \mathrm{~s}$ duration, non-overlapping windows spanning a $\sim 3$ to 5 min recording at each distance. Shown in red are the concurrent data from the fixed near-reef reference hydrophone (temporal trend). Dashed red lines indicate the $68 \%$ quantile range. These measurements show consistent sound levels $( \pm 1-2 \mathrm{~dB}$ re $1 \mu \mathrm{Pa}$ rms) during the transect survey. Due to equipment failure, no reference hydrophone data are available for Clam Shoal in 2010. Note the change in horizontal scale for different reef sites and years 
Table 2. Transmission loss coefficient $\left(C_{\mathrm{TL}}, \pm \mathrm{SE}\right)$ and source level (SL; 2-23 kHz band) estimates

\begin{tabular}{|lcc|}
\hline Recording survey & $C_{\mathrm{TL}}$ & SL (dB re 1 $\mu \mathrm{Pa} @ 1 \mathrm{~m})$ \\
\hline West Bay 2010 & $11.0 \pm 2.1$ & $120.0 \pm 4.7$ \\
Clam Shoal 2010 & $7.6 \pm 1.6$ & $108.8 \pm 3.6$ \\
West Bay 2011 & $12.1 \pm 1.7$ & $119.5 \pm 4.0$ \\
Clam Shoal 2011 & $8.9 \pm 0.83$ & $111.2 \pm 2.1$ \\
\hline
\end{tabular}

Although sound levels in the higher frequency band appear to be driven primarily by the abundance of snapping shrimp sounds, other acoustic sources unique to oyster reefs likely also contribute to the difference in spectral characteristics and acoustic diversity between reef and off-reef soundscapes. Certain invertebrates, such as urchins, can be a dominant sound source in New Zealand coastal habitats, creating a distinct chorus via their feeding activity (Radford et al. 2008a), and in a Pacific Ocean coral reef system, the interaction of hard-shelled crustaceans with coral substrate can produce a consistently detectable spectral peak (Freeman et al. 2013). It is possible that the activity of abundant oyster predators such as mud crabs (Panopeidae) and stone crabs Menippe mercenaria could similarly represent a significant sound source to our estuarine oyster reef soundscape as they crush oyster shells and interact with the hard substrate. Sounds associated with activity of these highdensity oyster reef organisms have yet to be characterized and compared to ambient recordings. An additional distinct soundscape component on reefs may be the oysters themselves producing sound upon closure of their valves. Another species of bivalve, the great scallop Pecten maximus, can make impulsive wide frequency cracking sounds centered between 2 and $3 \mathrm{kHz}$ when they close their shells (Di Iorio et al. 2012). It is unlikely that oysters would produce similarly loud sounds, as their valve movement is more restricted than that of scallops; however, any sounds they do make may be unique and potentially important in distinguishing the oyster reef soundscape. In addition to these reef-related biotic soundscape components, sound production due to waves and current interaction is likely increased over the shallower reef habitats, and the hard substrate of the reefs will reflect and scatter more sound energy than the softbottom sediments (Urick 1984).

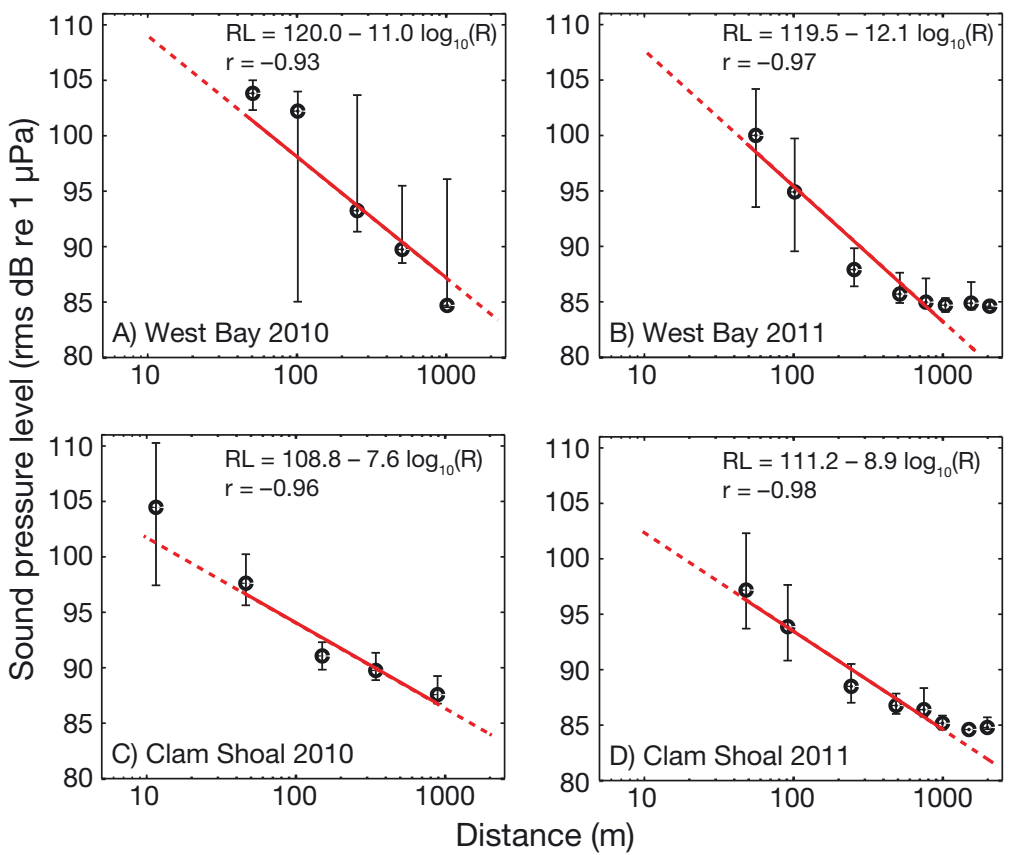

Fig. 9. Received sound pressure level (RL in $\mathrm{dB}$ re $1 \mu \mathrm{Pa}$ ) in the $2-23 \mathrm{kHz}$ band versus $\log _{10}$ of the range ( $\mathrm{R}$ in $\mathrm{m}$ ) from the reef. Squares and error bars show the median and $68 \%$ quantile ranges determined from using a sequence of $1 \mathrm{~s}$ duration, non-overlapping windows spanning a $\sim 3$ to $5 \mathrm{~min}$ recording at each station. The slope of the least-square regression line represents the transmission loss coefficient and the $y$-intercept the effective source level. The range of data used in the regression $(50-1000 \mathrm{~m})$ is indicated with a solid line

\section{Inter-reef acoustic variability}

In addition to establishing significant acoustic differences between adjacent reef and off-reef habitats, we found interesting between-reef differences that highlight the need for further investigation to link biological and physical habitat characteristics to soundscape patterns. The Crab Hole site showed a less pronounced 'reef signal,' lower acoustic diversity, and a smaller reef/off-reef acoustic dissimilarity compared to West Bay and Clam Shoal sites, a pattern most likely attributable to a lower abundance of snapping shrimp or other broadband sound producers. Given that Crab Hole has a much larger reef area with substantially more substrate compared to West Bay, and supports healthy populations of oysters and finfish (Mroch et al. 2012, Puckett \& Eggleston 2012), the lower sound levels and apparently lower snapping shrimp abundance are somewhat surprising. One possible reason for the acoustic disparity between the West Bay and Crab Hole oyster reserves is the difference in the configura- 
tion of the reef structure. The Crab Hole reserve consists of hundreds of high-relief $80 \mathrm{~m}^{2}$ mounds distributed throughout a large area, whereas the material placed at West Bay is relatively concentrated and clumped in banks, as well as several mounds, in a smaller area. The structure and shape of a reef could influence the abundance and activity of snapping shrimp, if it affects their level of inter- and intraspecific interaction, since their sounds are thought to be produced as agonistic and/or defense measures (Johnson et al. 1947, Knowlton \& Moulton 1963). Habitat configuration and patch distribution can also influence fish settlement, with clumped habitat leading to higher fish settlement (Morton \& Shima 2013); oyster reef configuration could similarly influence soniferous fish recruitment and, in turn, the reef soundscape.

An additional extension of this work will be to examine differences in oyster reef acoustic signatures across larger geographical scales, where species assemblages are known to differ. In particular, measurements of oyster reef soundscapes in regions where snapping shrimp are not known to occur (e.g. north of Chesapeake Bay on the east coast of the US; Williams 1984) could give insight into the importance of different soniferous organisms to ecological processes and help to evaluate when and where oyster reefs convey reliable acoustic signatures. Soundscape ecology is an emerging field of study, and a key component of future research will be collection of acoustic, biological, and physical data of reefs to investigate how specific reef characteristics relate to soundscape characteristics across ecologically relevant scales. If reef acoustic variation can be linked to specific reef characteristics (e.g. biodiversity, oyster density, fish abundance) that are indicative of reef health or productivity, this could provide a context for applying passive acoustic monitoring to oyster reef restoration projects to measure reef health.

\section{Soundscape measurement and analysis}

Due to the complex nature of sound fields, and because underwater acoustic recordings can be collected and interpreted using a variety of methods, careful application of techniques for sound measurement and analysis is critical to advancing the emerging discipline of marine soundscape ecology (McWilliam \& Hawkins 2013). In our study, the combination of longer-duration concurrent recordings in the reef and off-reef habitats with the replicated shorter-term reef sound propagation surveys allowed us to both directly detect differences in the acoustic characteristics between habitats, and to more closely examine the distances over which sound relates to benthic habitat type. The concurrent recording design, with relatively long recordings repeated at monthly intervals, increases our confidence that the samples are representative of the habitats, and reduces the concern of transient sounds or temporal instability affecting our interpretation of the soundscape. Previous marine soundscape studies have been somewhat limited in this sense because spatial comparisons were not based on concurrent or longer-term recordings, making it difficult to resolve habitat-type or site differences from temporal dynamics. Our comparatively extensive acoustic dataset demonstrates a considerable amount of temporal and inter-reef variation that warrants longer-term recording and additional spatial coverage to better understand these soundscapes and evaluate their ecological relevance. Clearly, accurately describing the acoustics of a habitat type or comparing sites based on single 2 to $5 \mathrm{~min}$ recordings is even more challenging, and we suggest that comprehensive approaches, including multiple hydrophones and temporal replication, should be used to the extent possible to better characterize the soundscapes of coastal and estuarine habitats. Limits to recording equipment and logistics reduce the number of sites and spatial coverage possible using a concurrent sampling approach, and therefore care must be taken in designing any sampling scheme to collect sufficient data to make appropriate inferences about the differences in acoustic characteristics over the time and space scales of ecological interest.

Techniques for soundscape analysis and interpretation, such as acoustic diversity indices, are recent developments that hold promise for revealing ecologically meaningful information from complex acoustic signals. However, because the relationship of these metrics to biodiversity has only been tested in terrestrial habitats (Sueur et al. 2008), more work is needed to confirm whether they can be a proxy for diversity of acoustic sources and biodiversity in marine environments. Moreover, while these indices provide a useful tool for simplifying soundscape comparisons, they should be used in conjunction with traditional acoustic analyses (e.g. inspection of acoustic power spectra, comparison of sound pressure levels) to identify specific differences in soundscape composition. This is particularly important in environments dominated by snapping shrimp sounds, because acoustic diversity indices can correlate with the number of snaps, and snaps potentially mask other sound sources (McWilliam \& Hawkins 2013). Additional testing 
of the diversity indices and further evaluation of the appropriateness of the terrestrial methodology (e.g. time window, frequency resolution) for marine datasets are needed to improve the application and interpretation of acoustic diversity indices in marine environments. Combining multiple measurement and analysis techniques is key to fully evaluating the ecological significance of soundscape variation. Moreover, studies of spatial acoustic heterogeneity must carefully consider the scales over which measurements are made, particularly when comparing locations or assessing the relevance of a changing acoustic environment to an ecological process such as settlement.

\section{SUMMARY}

Localized sub-tidal oyster reef habitats in Pamlico Sound differ acoustically from adjacent soft-bottom habitats, characterized primarily by higher levels of acoustic energy in frequency ranges associated with invertebrate-generated sounds $(2-23 \mathrm{kHz})$. A correspondence of ambient sound characteristics to particular habitat types has important implications for larval ecology, and more generally for the ecology and evolution of marine communities. Acoustic heterogeneity between and within habitats is a source of environmental heterogeneity that could influence habitat selection, dispersal and movement of many organisms, and be an indicator of the 'health' of a landscape (Pijanowski et al. 2011, Bormpoudakis et al. 2013). As has been proposed for terrestrial systems, habitat-related sound signatures in aquatic environments could offer a spatial structure for organisms to locate resources (Farina et al. 2011, Pijanowski et al. 2011). The results presented here indicate that an estuarine soundscape provides a reliable, localized indicator of benthic habitat type and potentially of more specific habitat characteristics. Together with results of studies showing that fish and invertebrates respond to habitat-related underwater sound (Montgomery et al. 2006, Radford et al. 2007, Stanley et al. 2012, Lillis et al. 2013), this suggests that the soundscape heterogeneity could influence orientation, settlement, and habitat selection for a variety of reefseeking organisms. Given that sound may play a role in recruitment processes, potentially affecting the replenishment of populations and marine community structure, it is essential that the variation in acoustic stimuli is appropriately characterized. Soundscape characterizations such as this, that establish the range of ambient sound characteristics present in an environment, are fundamental to provide the context for experimental studies of the influence of sound on marine ecological processes such as mate-finding, feeding, predator-prey interactions, habitat selection, and larval settlement. Furthermore, characterizations of habitat-related acoustic patterns at scales relevant to ecological processes are necessary to evaluate the potential adverse effects of anthropogenic noise or soundscape degradation on marine ecosystems.

Acknowledgements. We thank our field team (G. Plaia, R. Dunn, J. Peters, K. Pierson, R. Rindone, H. Eggleston, and B. Puckett) for assistance with the collection of field recordings. Thanks to T. Wolcott for assistance and use of equipment for acoustic recorder calibration, and to J. Luczkovich and D. Kamykowski for valuable feedback on this study. The manuscript was greatly improved by the constructive comments of 3 anonymous reviewers. Funding for the early stages of this project was generously provided by a National Shellfisheries Association Student Research Grant, a PADI Foundation Grant (\#5145), and American Academy of Underwater Sciences Scholarship to A.L. to support PhD research. This study was further supported by National Science Foundation Grant OCE-1234688.

\section{LITERATURE CITED}

Amorim MCP, Vasconcelos RO, Marques JF, Almada F (2006) Seasonal variation of sound production in the Lusitanian toadfish Halobatrachus didactylus. J Fish Biol 69:1892-1899

> Au WWL, Banks K (1998) The acoustics of the snapping shrimp Synalpheus parneomeris in Kaneohe Bay. J Acoust Soc Am 103:41-47

> Bormpoudakis D, Sueur J, Pantis JD (2013) Spatial heterogeneity of ambient sound at the habitat type level: ecological implications and applications. Landsc Ecol 28: 495-506

Boudreaux ML, Stiner JL, Walters LJ (2006) Biodiversity of sessile and motile macrofauna on intertidal oyster reefs in Mosquito Lagoon, Florida. J Shellfish Res 25:1079-1089

> Cato DH (1978) Marine biological choruses observed in tropical waters near Australia. J Acoust Soc Am 64: 736-743

> Cato DH (1980) Some unusual sounds of apparent biological origin responsible for sustained background noise in the Timor Sea. J Acoust Soc Am 68:1056-1060

Cato DH (1993) The biological contribution to the ambient noise in waters near Australia. Acoust Aust 20:76-80

Cato DH, Noad MJ, McCauley RD (2005) Passive acoustics as a key to the study of marine animals. In: Medwin $\mathrm{H}$ (ed) Sounds in the sea: from ocean acoustics to acoustical oceanography. Cambridge University Press, New York, NY, p 411-429

Chitre MA, Potter JR, Ong SH (2006) Optimal and nearoptimal signal detection in snapping shrimp dominated ambient noise. IEEE J Ocean Eng 31:497-503

Chitre M, Legg M, Koay TB (2012) Snapping shrimp dominated natural soundscape in Singapore waters. Contrib Mar Sci 2012:127-134 
Cotter A (2008) The 'soundscape' of the sea, underwater navigation, and why we should be listening more. In: Payne A, Cotter J, Potter T (eds) Advances in fisheries science: 50 years on from Beverton and Holt. Blackwell, Oxford, p 451-471

Di Iorio L, Gervaise C, Jaud V, Robson AA, Chauvaud L (2012) Hydrophone detects cracking sounds: nonintrusive monitoring of bivalve movement. J Exp Mar Biol Ecol 432-433:9-16

Etherington LL, Eggleston DB (2000) Large-scale blue crab recruitment: linking postlarval transport, post-settlement planktonic dispersal, and multiple nursery habitats. Mar Ecol Prog Ser 204:179-198

Everest FA (1948) Acoustical characteristics of noise produced by snapping shrimp. J Acoust Soc Am 20:137

Farina A, Lattanzi E, Malavasi R, Pieretti N, Piccioli L (2011) Avian soundscapes and cognitive landscapes: theory, application and ecological perspectives. Landsc Ecol 26: 1257-1267

Fay RR, Popper AN, Webb JF (2008) Fish bioacoustics. Springer, New York, NY

> Ferguson BG, Cleary JL (2001) In situ source level and source position estimates of biological transient signals produced by snapping shrimp in an underwater environment. J Acoust Soc Am 109:3031

Fine ML (1978) Seasonal and geographical variation of the mating call of the oyster toadfish Opsanus tau L. Oecologia 36:45-57

Fine ML, Thorson RF (2008) Use of passive acoustics for assessing behavioral interactions in individual toadfish. Trans Am Fish Soc 137:627-637

Freeman SE, Rohwer FL, Gregg A, Coleman L, Buckingham MJ (2013) On the origins of ambient biological sounds in shallow water tropical ecosystems. J Acoust Soc Am 133: 3396

- Gannon D (2007) Acoustic behavior of Atlantic croaker, Micropogonias undulatus (Sciaenidae). Copeia 2007: 193-204

Gasc A, Sueur J, Pavoine S, Pellens R, Grandcolas P (2013) Biodiversity sampling using a global acoustic approach: contrasting sites with microendemics in New Caledonia. PLoS ONE 8:e65311

$>$ Haase AT, Eggleston DB, Luettich RA, Weaver RJ, Puckett BJ (2012) Estuarine circulation and predicted oyster larval dispersal among a network of reserves. Estuar Coast Shelf Sci 101:33-43

> Johnson MW, Alton Everest F, Young RW (1947) The role of snapping shrimp (Crangon and Synalpheus) in the production of underwater noise in the sea. Biol Bull (Woods Hole) 93:122-138

Kalmijn AJ (1988) Hydrodynamic and acoustic field detection. In: Atema J, Fay RR, Popper AN, Tavolga WN (eds) Sensory biology of aquatic animals. Springer-Verlag, New York, NY, p 83-130

> Kennedy EV, Holderied MW, Mair JM, Guzman HM, Simpson SD (2010) Spatial patterns in reef-generated noise relate to habitats and communities: evidence from a Panamanian case study. J Exp Mar Biol Ecol 395:85-92

Knowlton RE, Moulton JM (1963) Sound production in the snapping shrimps Alpheus (Crangon) and Synalpheus. Biol Bull (Woods Hole) 125:311

Lande R (1996) Statistics and partitioning of species diversity, and similarity among multiple communities. Oikos 76:5-13

Lillis A, Eggleston DB, Bohnenstiehl DR (2013) Oyster larvae settle in response to habitat-associated underwater sounds. PLoS ONE 8:e79337

Luczkovich JJ, Sprague MW (2002) Using passive acoustics to monitor estuarine fish populations. Bioacoustics 12: 289-291

Luczkovich JJ, Pullinger RC, Johnson SE, Sprague MW (2008) Identifying sciaenid critical spawning habitats by the use of passive acoustics. Trans Am Fish Soc 137: $576-605$

Luettich RA Jr, Carr SD, Reynolds-Fleming JV, Fulcher CW, McNinch JE (2002) Semi-diurnal seiching in a shallow, microtidal lagoonal estuary. Cont Shelf Res 22:1669-1681

> McCauley RD, Cato DH (2000) Patterns of fish calling in a nearshore environment in the Great Barrier Reef. Philos Trans R Soc Lond B Biol Sci 355:1289-1293

McWilliam JN, Hawkins AD (2013) A comparison of inshore marine soundscapes. J Exp Mar Biol Ecol 446:166-176

> Montgomery JC, Jeffs A, Simpson SD, Meekan M, Tindle C (2006) Sound as an orientation cue for the pelagic larvae of reef fishes and decapod crustaceans. Adv Mar Biol 51: 143-196

> Morton DN, Shima JS (2013) Habitat configuration and availability influences the settlement of temperate reef fishes (Tripterygiidae). J Exp Mar Biol Ecol 449:215-220

> Moulton JM (1960) Swimming sounds and the schooling of fishes. Biol Bull (Woods Hole) 119:210-223

> Mroch RM III, Eggleston DB, Puckett BJ (2012) Spatiotemporal variation in oyster fecundity and reproductive output in a network of no-take reserves. J Shellfish Res 31:1091-1101

> Patek SN, Shipp LE, Staaterman ER (2009) The acoustics and acoustic behavior of the California spiny lobster (Panulirus interruptus). J Acoust Soc Am 125:3434-3443

Pierson K, Eggleston DB (2014) Response of estuarine fish to large-scale oyster reef restoration. Trans Am Fish Soc 143:273-288

Pietrafesa LJ, Janowitz GS (1988) Physical oceanographic processes affecting larval transport around and through North Carolina inlets. Am Fish Soc Symp 3:34-50

Pietrafesa LJ, Janowitz GS, Miller JM, Noble EB, Ross SW, Epperly SP (1986) Abiotic factors influencing the spatial and temporal variability of juvenile fish in Pamlico Sound, North Carolina. In: Wolfe DA (ed) Estuarine variability. Academic Press, London, p 341-352

Pijanowski BC, Villanueva-Rivera LJ, Dumyahn SL, Farina A and others (2011) Soundscape ecology: the science of sound in the landscape. Bioscience 61:203-216

> Puckett BJ, Eggleston DB (2012) Oyster demographics in a network of no-take reserves: recruitment, growth, survival, and density dependence. Mar Coast Fish 4:605-627

Radford CA, Jeffs AG, Montgomery JC (2007) Directional swimming behavior by five species of crab postlarvae in response to reef sound. Bull Mar Sci 80:369-378

Radford C, Jeffs A, Tindle C, Montgomery JC (2008a) Resonating sea urchin skeletons create coastal choruses. Mar Ecol Prog Ser 362:37-43

Radford CA, Jeffs AG, Tindle CT, Montgomery JC (2008b) Temporal patterns in ambient noise of biological origin from a shallow water temperate reef. Oecologia 156: 921-929

> Radford CA, Stanley JA, Tindle CT, Montgomery JC, Jeffs AG (2010) Localised coastal habitats have distinct underwater sound signatures. Mar Ecol Prog Ser 401:21-29

Radford C, Tindle C, Montgomery JC, Jeffs AG (2011) Modelling a reef as an extended sound source increases the 
predicted range at which reef noise may be heard by fish larvae. Mar Ecol Prog Ser 438:167-174

Ramcharitar J, Gannon DP, Popper AN (2006) Bioacoustics of fishes of the family Sciaenidae (croakers and drums). Trans Am Fish Soc 135:1409-1431

Rindone RR, Eggleston DB (2011) Predator-prey dynamics between recently established stone crabs (Menippe spp.) and oyster prey (Crassostrea virginica). J Exp Mar Biol Ecol 407:216-225

Rogers PH, Cox M (1988) Underwater sound as a biological stimulus. In: Atema J, Fay RR, Popper AN, Tavolga WN (eds) Sensory biology of aquatic animals. SpringerVerlag, New York, NY, p 131-149

Simpson SD, Meekan M, Montgomery J, McCauley R, Jeffs A (2005) Homeward sound. Science 308:221

Slabbekoorn H, Bouton N (2008) Soundscape orientation: a new field in need of sound investigation. Anim Behav 76:e5-e8

Sprague MW, Luczkovich JJ, Johnson SE (1998) Using fish sounds to identify spawning activity of weakfish (Cynoscion regalis) and red drum (Sciaenops ocellatus) in nature. J Acoust Soc Am 103:3001

Sprague MW, Luczkovich JJ, Pullinger RC, Johnson SE, Jenkins T, Daniel HJ III (2000) Using spectral analysis to identify drumming sounds of some North Carolina fishes in the family Sciaenidae. J Elisha Mitchell Sci Soc 116: 124-145

Staaterman E, Rice AN, Mann DA, Paris CB (2013) Soundscapes from a Tropical Eastern Pacific reef and a Caribbean Sea reef. Coral Reefs 32:553-557

Stanley JA, Radford CA, Jeffs AG (2012) Location, location, location: finding a suitable home among the noise. Proc $\mathrm{R}$

Editorial responsibility: Nicholas Tolimieri,

Seattle, Washington, USA
Soc Lond B Biol Sci 279:3622-3631

> Stephens MA (1974) EDF statistics for goodness of fit and some comparisons. J Am Stat Assoc 69:730-737

Sueur J, Pavoine S, Hamerlynck O, Duvail S (2008) Rapid acoustic survey for biodiversity appraisal. PLoS ONE 3: e4065

Urick RJ (1983) Principles of underwater sound. Peninsula Publishing, New York, NY

Urick RJ (1984) Ambient noise in the sea. Report to the Undersea Warfare Technology Office, Washington, DC

Versluis M, Schmitz B, von der Heydt A, Lohse D (2000) How snapping shrimp snap: through cavitating bubbles. Science 289:2114-2117

White ME, Wilson EA (1996) Predators, pests, and competitors. In: Kennedy VS, Newell RIE, Eble AF (eds) The eastern oyster: Crassostrea virginica. University of Maryland Sea Grant College, College Park, MD, p 559-579

- Wilkens SL, Stanley JA, Jeffs AG (2012) Induction of settlement in mussel (Perna canaliculus) larvae by vessel noise. Biofouling 28:65-72

Williams AB (1984) Shrimps, lobsters, and crabs of the Atlantic Coast of the Eastern United States, Maine to Florida. Smithsonian Institution Press, Washington, DC

Xie L, Eggleston DB (1999) Computer simulations of windinduced estuarine circulation patterns and estuaryshelf exchange processes: the potential role of wind forcing on larval transport. Estuar Coast Shelf Sci 49: 221-234

Xie L, Pietrafesa LJ (1999) Systemwide modeling of wind and density driven circulation in Croatan-AlbemarlePamlico Estuary System. Part I: Model configuration and testing. J Coast Res 15:1163-1177

Submitted: January 1, 2014; Accepted: March 28, 2014

Proofs received from author(s): May 14, 2014 